\title{
O PAPEL DO PROFESSOR NA EDUCAÇÃO SEXUAL DE ADOLESCENTES
}

Marília Lima de Holanda ${ }^{1}$, Mirna Albuquerque Frota ${ }^{2}$, Maria de Fátima Antero Sousa Machado ${ }^{3}$, Neiva Francenely

Cunha Vieira ${ }^{4}$

RESUMO: Estudo qualitativo com o objetivo de conhecer a percepção do professor como educador de adolescentes em relação a sexo/sexualidade. Os dados foram coletados por meio de entrevista semiestruturada e analisados conforme análise de conteúdo de Bardin, emergindo as categorias: "sexualidade na escola: percepções e práticas do professor"; "fatores que dificultam a educação sexual na escola"; e "parceria família e escola para o desenvolvimento da educação sexual na escola”. Os resultados revelaram que alguns professores se percebem importantes na educação sexual de alunos; porém, outros transferem-na para outras instituições. Conclui-se que a escola é local privilegiado para a educação sexual de adolescentes; entretanto, os professores encontram desafios para desenvolver esta atividade.

PALAVRAS-CHAVE: Saúde escolar; Promoção da saúde; Educação sexual.

\section{TEACHER'S ROLE IN THE SEXUAL EDUCATION OF ADOLESCENTS}

\begin{abstract}
This qualitative study aimed to know the perception of the teacher as educator of adolescents about sex and sexuality. Data were collected through semi structured interviews and analyzed according to Bardin's content analysis. Emerging categories: "sexuality at school: perceptions and practices of the teacher"; "factors which make sexual education in school difficult"; "family and school partnership for the development of sexual education in school. "The results revealed that some teachers perceive themselves as important in sexual education for students, but others transfer it to other institutions. It is concluded that the school is a privileged place for the sexual education of adolescents, however teachers face challenges in developing this activity.
\end{abstract}

KEYWORDS: School health; Health promotion; Sexual education.

\section{EL PAPEL DEL PROFESOR EN LA EDUCACIÓN SEXUAL DE ADOLECIENTES}

RESUMEN: Estudio cualitativo con objetivo de conocer la percepción del profesor como educador de adolecientes acerca de sexo/sexualidad. Los datos fueron recogidos por medio de entrevista semiestructurada y analizados de acuerdo al análisis de contenido de Bardin, surgiendo las categorías: "sexualidad en la escuela: percepciones y prácticas del profesor"; "factores que dificultan la educación sexual en la escuela"; "sociedad familia y escuela para el desarrollo de la educación sexual en la escuela". Los resultados revelaron que algunos profesores se perciben importantes en la educación sexual de alumnos, pero otros creen que éste es un papel para otras instituciones. Se concluye que la escuela es un sitio privilegiado para la educación sexual de adolecientes, pero los profesores encuentran desafíos para desarrollar esa actividade.

PALABRAS CLAVE: Salud escolar; Promoción de la salud; Educación sexual.

${ }^{1}$ Enfermeira. Integrante do Grupo de Pesquisa Família, Ensino, Pesquisa e Extensão, da Universidade Federal do Ceará-FAMEPE/ UFC. Enfermeira do Município de Fortaleza/CE.

${ }^{2}$ Enfermeira. Doutor em Enfermagem. Professor Adjunto do Curso de Graduação e do Programa de Pós-Graduação da Universidade de Fortaleza-UNIFOR. Líder do Núcleo de Pesquisa e Estudo em Saúde da Criança-NUPESC/CNPq.

${ }^{3}$ Enfermeira. Doutor em Enfermagem. Professor do Curso de Graduação em Enfermagem da UNIFOR. Membro do FAMEPE/UFC. ${ }^{4}$ Enfermeira. Doutor em Educação em Saúde. Professor Adjunto do Curso de Graduação em Enfermagem da Universidade Federal do Ceará-UFC. Membro do FAMEPE/UFC.

\section{Autor correspondente:}

Mirna Albuquerque Frota

Universidade de Fortaleza

Rua Manoel Jacaré, 150 - 60175110 - Fortaleza-CE-Brasil Recebido: 04/10/09

E-mail:mirnafrota@unifor.br 


\section{INTRODUÇÃO}

A incidência das Doenças Sexualmente Transmissíveis (DST) tem aumentado na população em geral, e entre adolescentes o número de contaminados é preocupante. Quase metade dos novos casos de Aids ocorre entre os jovens com idade entre 15 e 24 anos. Considerando que a maioria dos doentes está na faixa dos 20 anos, conclui-se que a soroconversão ocorre, majoritariamente, na adolescência, considerando-se o período assintomático ${ }^{(1)}$. Destaca-se, então, a Educação em Saúde na escola como estratégia para a promoção da saúde dessa parcela da população, e o professor passa a ter papel fundamental como agente sensibilizador dos jovens alunos.

O conhecimento dos adolescentes sobre medidas de prevenção de DST/Aids não parece ser suficiente para assegurar comportamentos sexuais saudáveis ${ }^{(2)}$. A maior parte desse conhecimento vem da mídia e consiste em informação superficial, que não consegue sensibilizar o jovem para a adoção de atitude livre de risco.

O governo brasileiro, por meio dos Parâmetros Curriculares Nacionais (PCN) estabelecidos pelo Ministério da Educação e Cultura (MEC), na tentativa de encontrar respostas para a problemática das consequências da iniciação sexual precoce dos adolescentes e contribuir com a redução das estatísticas de DST / Aids e gravidez na adolescência, elaborou a proposta de incluir no currículo da escola a orientação sexual como disciplina. Esta medida não deixa de ser iniciativa da inserção do tema "sexualidade" na escola, mostrando a sua relevância para a população $0^{(3)}$.

Pesquisas demonstram que a escola representa o espaço social significativo de promoção da saúde, por ser o local onde os alunos permanecem grande parte do dia. Elas apontam a escola, depois do seio familiar, como local privilegiado para o desenvolvimento de ações de informações e Educação em Saúde com o objetivo de incentivar estilos de vida saudáveis. Salienta-se a necessidade de realizar ações de Educação em Saúde neste contexto, o que permite integrar os profissionais da escola na orientação sobre fatores de risco para doenças ${ }^{(4-5)}$.

Outro estudo garante que o crédito da escola pode ser considerado maior do que o da família na educação sexual de adolescentes; quando a família se empenha nesse processo, o número de adolescentes instruídos é menor do que se o professor/educador fizer o mesmo. Neste contexto, o professor torna-se o profissional adequado para alcançar grande número de adolescentes $^{(5)}$. Sem questionar qual das instituições, se a escola ou a família, tem mais mérito na realização da educação sexual, afirma-se que ambas têm valor para a abordagem do tema.

Os pais ainda não dão a devida atenção à sexualidade dos filhos o que aumenta a responsabilidade dos professores na educação sexual do aluno. Pressupõese que esta seja alicerçada em um tripé composto por informações provenientes da família, da escola e de fontes que, embora não sejam capazes de sensibilizar o jovem a assumir comportamento livre de riscos, como amigos, televisão, revista e internet estão presentes. Se a família não assume o papel na educação sexual do jovem, a responsabilidade recai sobre a escola, na figura do professor ${ }^{(6)}$.

É neste contexto que se compreende a escola como foco de atenção à promoção da saúde da criança e do adolescente. Assim, buscou-se conhecer o papel dos professores na educação sexual de adolescentes em uma escola pública.

\section{METODOLOGIA}

Este é um estudo de natureza qualitativa, de caráter descritivo, desenvolvido em uma escola da rede estadual de ensino, localizada no Município de Fortaleza/CE, que tem vínculo com o projeto de extensão AIDS: Educação e Prevenção, do Departamento de Enfermagem da Faculdade de Farmácia, Odontologia e Enfermagem da Universidade Federal do Ceará. Este trabalho faz parte de um Projeto de Pesquisa-Educação em Saúde no Contexto da Promoção Humana - uma investigação na Enfermagem, e conta com o apoio financeiro do Conselho Nacional de Desenvolvimento Científico e Tecnológico (CNPq).

A pesquisa foi realizada no primeiro semestre do ano de 2005, com todos os professores de alunos na faixa etária compreendida entre 10 e 18 anos de idade que trabalhavam no turno da manhã e/ou tarde e consentiram em participar da pesquisa. Contamos com 11 participantes: 8 eram do sexo feminino e três do masculino, e se encontravam na faixa etária entre 31 a 50 anos. As pesquisadoras fizeram contato prévio, mediante a realização de oficinas educativas com adolescentes, pais e professores, para a integração do Projeto com a Escola, com o intuito de estabelecer um vínculo entre as pesquisadoras e o campo de estudo.

Para a coleta de dados foi utilizado um roteiro semiestruturado para nortear as entrevistas, as quais 
foram gravadas, em fitas cassetes, mediante autorização dos sujeitos.

A análise dos dados foi realizada por meio de três etapas: pré-análise (organização dos dados), análise (categorização) e interpretação ${ }^{(7)}$, utilizando literatura na análise referente a adolescente, educação sexual, bem como aos PCN. Os dados foram organizados em quatro categorias que emergiram das falas dos entrevistados: "Sexualidade na escola: percepções e práticas do professor"; "Fatores que dificultam o processo de educação sexual na escola"; "Fatores que facilitam o processo de educação sexual na escola" e "Parceria família e escola para o desenvolvimento da educação sexual na escola”.

A pesquisa cumpriu todos os preceitos éticos e foi aprovada pelo Comitê de Ética em Pesquisa do Complexo Hospitalar da Universidade Federal do Ceará (COMEPE), sob o parecer n. 302/04.

\section{RESULTADOS E DISCUSSÃO}

A inserção do professor na educação sexual do adolescente se configura, neste estudo, a partir das categorias emergidas das falas dos entrevistados. A seguir, apresentam-se as categorias e o arcabouço teórico da análise.

\section{Sexualidade na escola: percepções e práticas do professor}

Em estudo realizado com 100 professores da Rede de Ensino Público do Município de Jandira, no Estado de São Paulo, detectou-se que 99\% dos participantes consideravam a orientação sexual na escola importante à medida que contribui para conscientizar os alunos, preparando-os para a vida ${ }^{(8)}$. Em concordância, nesta pesquisa os entrevistados relataram que a educação sexual de alunos adolescentes faz parte de suas obrigações como educadores e consideram-se peça fundamental neste processo:

Eu acho de suma responsabilidade e importância, pois eles precisam bastante dessa orientação; e também como uma necessidade para que eles possam realmente crescer em um ambiente sadio. (Professor 4)

Eu acho que é uma obrigação do professor alertar, $e$ até faz parte do conteúdo de alguns livros, né? Eu acho que eles têm a obrigação de se informar e de aprender como falar com os alunos o assunto. (Professor 1)
Com o conhecimento, ou não, da proposta de orientação sexual dos $\mathrm{PCN}$, alguns professores contribuem para o alcance do objetivo que é incentivar alunos a se envolver e exercer a sexualidade com prazer e responsabilidade ${ }^{(3)}$. Neste contexto, eles orientam com vistas a prevenir possíveis problemas decorrentes da expressão da sexualidade, valorizando a promoção da saúde, por meio da Educação. Tal fato pode ser constatado nas falas:

Assim que o professor tiver consciência que ele é um agente que pode evitar muitos problemas na sexualidade da criança ou do adolescente, ele é um instrumento de grande valia. (Professor 7)

[...] até de relação de prevenção de doenças, com relação também a evitar ter filhos na adolescência. Tudo isso pode ser abordado. (Professor 9)

Algumas falas denotam, porém, uma visão reducionista da ação do professor na formação global do aluno, desperdiçando a oportunidade de participar da prevenção de possíveis agravos decorrentes da desinformação dos jovens. Como estes educadores atuam com adolescentes, torna-se necessário que eles adotem uma visão ampliada sobre as questões que permeiam esta fase da vida.

Eu acho que tem que ser abordado, sim, não exatamente assim um papel, mas, se surgir, acontecer um fato, alguma coisa assim. E sempre que possivel na disciplina levar um texto, alguma coisa relacionada para ajudar. (Professor 3)

Conversando quando ele nota que o adolescente já está fazendo algo de errado que está relacionado ao sexo. (Professor 5)

Foi referido, pelos participantes, o fato de que o tema a ser discutido surge da necessidade do aluno, o que reforça a concepção de processo educativo, que deve acontecer com base na demanda da clientela, visando o envolvimento e o interesse do aluno:

Da forma que for necessária, de acordo com a necessidade da turma, com que o aluno estiver precisando no momento. Não é necessário preparar aulas especificas e não ver a realidade em que o aluno está vivenciando. (Professor 7) 
A partir da curiosidade dos alunos e também a partir daquilo que, dependendo da série, o professor, o educador, achar que deve iniciar a falar. (Professor 11)

Percebe-se a concordância do professor com a abordagem proposta pelos PCN, ao sugerir que a educação sexual ocorra de forma clara, porém sutil, de acordo com os questionamentos surgidos, explorando o cotidiano, sem o intuito de estimular ou reprimir. O professor deve satisfazer as curiosidades dos alunos com franqueza, à medida que forem surgindo os problemas, por meio de vocabulário simples e compreensível $^{(9)}$.

O papel formador na educação sexual do adolescente não é tratado de forma ampla no âmbito familiar, portanto, o assunto merece atenção da escola, conforme a percepção dos professores:

[...] os pais não conversam com os filhos, na sua maioria em casa, então compete à escola orientar bem para que realmente a formação seja completa dos educandos. (Professor 11)

Educação em Saúde é proporcionar ao indivíduo critérios para escolher a alternativa mais saudável para o próprio bem-estar, acarretando alterações de comportamento e estilo de vida. Essas mudanças acontecem desde o momento em que as pessoas tomam consciência das suas razões e benefícios ${ }^{(10)}$. Desta forma, cabe à escola, na pessoa do professor, abordar os diversos pontos de vista, valores, crenças e atitudes a respeito da sexualidade, sem emitir juízo, para auxiliar o aluno a refletir sobre a temática, e assim elaborar a própria opinião. É uma forma diferente da usada pelos pais, que dão o direcionamento para que os filhos ajam como eles esperam, sem proporcionar, por vezes, momentos de reflexão.

No entanto, alguns professores buscaram reduzir sua responsabilidade como educador; para eles, o papel da educação sexual foi atribuído a outras instituições ou a educadores de determinadas disciplinas escolares, justificando serem aqueles possuidores de competências para desenvolver estas atividades:

Acho, principalmente nas áreas de Ciências, né? Porque no campo de Português, a gente só aborda quando tem algum texto relacionado à sexualidade. (Professor 2)

Papel exato eu acho que não! Eu acho que a psicopedagogia, a igreja, não só a escola, a família, a própria familia. Eu acho que também tem que vir uma orientação primeiro de casa. (Professor 3)

Nota-se que a educação sexual na escola pesquisada é feita, principalmente, por professores de disciplinas específicas, o que prejudica a interdisciplinaridade defendida pelos PCN:

Eu sempre trabalho, porque eu trabalho com Biologia, então é uma área mais acessivel. (Professor 1)

Particularmente, eu já tenho feito o exercício do desenvolvimento do assunto da sexualidade, da prevenção de doenças transmitidas sexualmente e da tão temerosa Aids, através de leituras de textos. Por ser professor de Português, para mim é mais fácil. (Professor 10)

Notou-se a tendência de dar à sexualidade um enfoque biologicista. As escolas têm a tendência de trabalhar a sexualidade com base nas Ciências Naturais, abordando questões de reprodução humana, anatomia e fisiologia do corpo humano. De acordo com os PCN, essa abordagem não satisfaz a ansiedade e a curiosidade da criança, nem o interesse dos adolescentes, pois enfoca o corpo biológico e não inclui a dimensão da sexualidade, e essa não-satisfação do aluno produz ansiedade, tensão e inibição da capacidade investigativa ${ }^{(3)}$.

\section{Fatores que dificultam a educação sexual na escola}

A dificuldade de abordar o tema na escola é relatada, seja por carência de materiais didáticos ou por falta de formação adequada (pessoal capacitado):

É utopia dizer que a gente pode trabalhar mais de forma aberta com eles. Não dá! Então, o que a gente pode trabalhar em escola é debater em sala de aula, trazendo algum vídeo informativo e só. Não tem mais como trabalhar em sala. (Professor 2)

Os professores, apesar de perceberem a necessidade de adotar uma posição mais liberal para o tratamento das questões relativas à sexualidade na escola, continuam sem subsídios para trabalhar tais questões. Sabe-se que as escolas enfrentam dificuldades para inserir novas práticas em educação sexual e, muitas vezes deixam, de oferecer um espaço para que ocorram debates sobre saúde reprodutiva e sexualidade, de forma contínua ${ }^{(8,11)}$. Sendo assim, acabam por 
relegá-la a um enfoque biológico, que tem a função de preservar o educador frente aos alunos, com relação aos próprios questionamentos, receios e ansiedades.

A família surge, com certa frequência, como fator que gera obstáculos à realização da educação sexual na escola. De acordo com a percepção do professor, o que poderia ser instrumento de apoio para a realização desse processo com adolescentes, se torna obstáculo:

A gente tem medo dos pais não concordarem com a história. Posso ir de encontro aos pais, a educação que eles têm em casa. Eu fico preocupada com a reação dos pais: achar que a gente pode estar interferindo na informação que eles dão. (Professor 1)

A gente não sabe qual vai ser a reação do aluno. Muitas vezes eles ficam calados, ouvindo, mas em casa eles podem até colocar pra mãe de uma forma: "Ah, a minha professora fala sobre sexo". Então, às vezes pode, até prejudicar o profissional. (Professor 2)

Ainda nas escolas existe esse receio: as mães acham que, quando a gente questiona esse tema, é como se fosse imoralidade, por que as pessoas ainda não estão preparadas. Ainda são aquelas pessoas que tem aquela cabeça: "Aí, já vão ensinar na escola pro meu filho coisa imoral". Achando que o sexo ainda é uma coisa feia, nojenta. (Professor 4)

Esse receio deve ser superado, pois os PCN, já em 2001, citavam que na atualidade os pais reivindicam a orientação sexual nas escolas. Já em 1993, o Instituto Datafolha divulgou pesquisa realizada em dez capitais brasileiras, constatando que $86 \%$ das 5.076 pessoas ouvidas eram favoráveis à inclusão de orientação sexual no currículo escolar ${ }^{(4)}$.

A escola ganha maior responsabilidade quando os pais não se dispõem ou possuem bloqueio para abordar o tema sexualidade com os filhos, porém, a escola e a família têm papéis diferentes e complementares e não substitutos sobre isso. A inexperiência e a insegurança acerca de estar preparado para abordar a temática constituíram outro aspecto encontrado pelos professores como elemento que compromete a prática da educação sexual na escola ${ }^{(8)}$ :

A questão também é o tempo que a gente não tem para o planejamento, que entre esses temas, é pra entrar. Mas, acaba a gente deixando, acaba ficando um pouco pra trás. Pode acontecer também de algum assunto novo, de alguma coisa que eu possa até não estar por dentro, justamente por falta desse tempo que a gente não tem pra gente ler. A gente não está tendo muito tempo pra ler coisas novas, coisas diferentes. Talvez até os alunos são mais entendidos desses assuntos do que a gente, sabem de coisas justamente por eles participarem dessas palestras e a gente geralmente não participa, porque geralmente é voltada mais para eles. (Professor 3)

Não acho fácil! Eu não estou preparada pra isso, [...] insegurança mesmo. (Professor 6)

Os professores não foram formados na universidade e nem tiveram cursos para tratar desse assunto muito delicado. No meu caso específico, que sou formado em Geografia, porque o que eu sei sobre educação sexual foi o que eu li. Nunca recebi um curso sequer [sobre] como abordar esse tema em sala de aula, embora no nosso curso de Geografia a gente tenha que abordar quando vai falar de população, crescimento populacional e tudo. Não deixa de vir a tona esses problemas do cotidiano, da prostituição infantil, da gravidez na adolescência, que realmente a gente tem que estar preparado para tratar desse assunto. Mas, professor propriamente dito, nós temos pouquíssimos na escola, preparados para tratar desses assuntos. (Professor 11)

A escola é a instituição mais indicada pelas autoridades educacionais, pelos especialistas e pela sociedade em geral como campo fértil e ideal para se dar orientação sexual ${ }^{(12-13)}$. Porém, faltam cursos de aprimoramento e aprofundamento teórico e reflexivo para os professores, com a finalidade de subsidiar a prática no trabalho com os adolescentes, pois a maioria não está preparada para conduzir discussões sobre sexualidade e, muitas vezes, assumem atitudes discriminatórias com os alunos ${ }^{(5,11)}$. Neste sentido, a escola representa o locus por excelência para abordar o tema sexualidade com jovens; entretanto, se faz necessária a preparação dos educadores nessa área, objetivando melhor formação do adolescente.

\section{Parceria família e escola para o desenvolvimento da educação sexual na escola}

Detentores do conhecimento de que a família pode colaborar para o desenvolvimento da educação sexual de crianças e adolescentes junto à escola, inves- 
tigou-se a participação desta instituição no processo, porém, os professores relataram que a família não é estimulada a participar de atividades que envolvam o tema sexualidade na escola:

Não, não dá, não! Eles passam o dia trabalhando, muitas vezes, e outra coisa: tem alunos aqui que moram com a avó, que já é velha! Não dá, não! (Professor 2)

Nas atividades da escola, os pais e a comunidade sempre são chamados a participar, mas em atividade relacionada à sexualidade, eu não sei, não, acho que não. (Professor 5)

Nós fizemos, uma vez, uma palestra que os pais foram convidados, sobre familia, um tema bem abrangente [...]. Mas sobre a sexualidade assim em específico ainda não [...]. (Professor 8)

Realmente, a familia ainda está um pouco distante, despreocupada com esse tema específico dentro da escola, quando na realidade são temas importantíssimo que a escola tem que chamar os pais para discutir e debater e orientar como é que tem que ser tratada em casa. (Professor 11)

Independentemente da participação familiar no processo educativo, a sexualidade é debatida na sociedade e nos meios de comunicação, como a televisão, o rádio e a Internet, que proporcionam ao adolescente inúmeras informações desencontradas sobre a sexualidade e influenciam o comportamento ${ }^{(9)}$.

Nenhuma organização é capaz de, sozinha, realizar ações que assegurem saúde e desenvolvimento pleno dos adolescentes. A família representa um dos eixos no desenvolvimento da orientação sexual de adolescentes, portanto, acredita-se que o sucesso da orientação sexual depende das alianças e parcerias intersetoriais que possam valorizar as potencialidades e reduzir as limitações de cada setor ${ }^{(14)}$. Destaca-se a importância da articulação dos setores saúde e educação, além da participação da família para a promoção da saúde dos adolescentes.

\section{CONSIDERAÇÕES FINAIS}

A educação sexual é prioritária no que se refere ao desenvolvimento da sexualidade de forma saudável, livre dos riscos das DST/Aids e da gravidez indesejada e/ou precoce. A família representa competência prioritária nesta educação, que deveria se iniciar no âmbito familiar. Muitas vezes, no entanto, a família não consegue cumprir tal atividade e transfere a responsabilidade à escola.

Fala-se em educação sexual na escola e logo os professores ganham posição ideal para desenvolver tal processo. Os professores valorizam a orientação e a conscientização dos alunos, preparando-os para a vida, porém, enfrentam obstáculos ao desempenhar a função na orientação sexual desses estudantes.

Evidenciou-se que a atribuição do professor na orientação sexual do adolescente está permeada de fatores que impedem o desenvolvimento desta prática conforme a orientação dos PCN. Esta prática está voltada com ênfase ao modelo biologisista, associado às disciplinas de Biologia e Ciências, o que reduz a possibilidade de realizar a prevenção de agravos, decorrentes da sexualidade exercida de forma imprudente, e de estimular comportamentos sexuais saudáveis. A abordagem de temas que envolvem a sexualidade humana, diferentemente dos conteúdos dos livros, requer do professor sensibilidade, habilidade, constante aprendizado e atualização.

Fatores como o despreparo e a insegurança para abordar a temática e os preconceitos e tabus presentes nos pais e professores são geradores de barreiras para a realização de estratégias que garantam a formação da sexualidade sadia e a promoção da saúde dos adolescentes.

Considera-se urgente priorizar a educação continuada dos profissionais que trabalham diretamente com adolescentes, não apenas os professores, mas também os que estão no setor saúde, com capacitação sobre sexualidade, a fim de subsidiar a prática na abordagem da temática com adolescentes. Da mesma forma, é conveniente que haja maior integração entre os setores saúde e educação, visando a valorizar a educação sexual e a promoção da saúde, oferecendo oportunidades de orientações e reflexões.

\section{REFERÊNCIAS}

1. Bogaski NT, Schirmer J, Barbieri M. A prevençäo das DST/AIDS entre adolescentes. Acta Paul Enferm.2000;13(1):18-26.

2. Vieira NFC, Paiva TCH, Sherlock MSM. Sexualidade, DST/AIDS e adolescência: não quero falar, tenho vergonha. DST - JBras Doenças Sex Transm. 2001;13(4):46-51. 
3. Ministério da Educação e do Desporto (BR). Parâmetros Curriculares Nacionais. Pluralidade cultural e orientação sexual - Temas transversais. v. 10. Brasília (DF): Ministério da Educação e do Desporto; 1997.

4. Dimenstein G. Estudo relaciona falta de escolaridade com gravidez. Folha de São Paulo. 1999 out 4; A4.

5. Santos Júnior JD. Fatores etiológicos relacionados a gravidez na adolescência; vulnerabilidade e maternidade. In: Ministério da Saúde (BR). Secretaria de Política de Saúde. Cadernos juventude, saúde e desenvolvimento. v.1. Brasília (DF): MS; 1999. p.223-9.

6. Holanda ML, Machado MFAS, Vieira NFC, Barroso MGT. Compreensão dos pais sobre exposição dos filhos aos riscos das DST/Aids. Rene.2006;7(1):27-34.

7. Bardin L. Análise de conteúdo. $3^{\mathrm{a}}$ ed. Lisboa: Edições 70; 2004.

8. Jardim DP, Brêtas JRS. Orientação sexual na escola: a concepção dos professores de Jandira - SP. Rev Bras Enferm.2006;59(2):157-62.

9. Nunes C, Silva E. A educação sexual da criança. Campinas: Autores Associados; 2000.

10. Girondi JBR, Nothaft SCS, Mallmann FMB. A metodologia problematizadora utilizada pelo enfermeiro na educação sexual de adolescentes. Cogitare Enferm. 2006;11(2):161-5.

11. Louro GL. Segredos e mentiras do currículo sexualidade e gênero nas práticas escolares. In: Silva LH. A escola cidadã no contexto da globalização. Petrópolis: Vozes; 1998. p. 33-47.

12. Suplicy M. Sexo se aprende na escola. São Paulo: Olho d'Água; 1998.

13. Ribeiro M. Educação sexual: novas idéias, novas conquistas. Rio de Janeiro: Rosa dos Tempos; 1993.

14. Ministério da Saúde (BR). Secretaria de Atenção à Saúde. Saúde integral de adolescentes e jovens: orientações para a organização de serviços de saúde. Brasília: 2005. 